\title{
Evaluation of Diversity of Soil Invertebrate Communities Near Forests of Gohagoda and Udawattakele in Kandy, Sri Lanka
}

\author{
Nijamdeen T.W.G.F.M. ${ }^{*}$, Weerakoon K.C. and Diyes G.C.P. \\ Department of Zoology, The Open University of Sri Lanka,Polgolla, Sri Lanka \\ *fathimamafaziya@gmail.com
}

\begin{abstract}
Soil faunal activity is essential for the functioning of all terrestrial ecosystems. Soil fauna are important in the physical and chemical transformation of litter, the maintenance of soil fertility and sustained productivity. By products of human activities affect the proper functioning of the soil fauna with a concomitant decrease in long term soil productivity. The fauna could be used as early indicators of changes brought about in soil properties by pollutants. In Sri Lanka studies of this nature are lacking and even baseline data against which changes could be measured are not yet available. Evaluation of possible indicator organisms coupled with soil chemical analysis to examine soil pollution is crucial. A field experiment was set up in Kandy in two forest areas near the Gohagoda dumping site and the Udawattakele forest reserve area to investigate the soil and leaf litter invertebrates.
\end{abstract}

The soil invertebrate fauna were extracted in both sampling sites by using $\mathrm{NaCl}$ floatation method and Baermann funnel. The leaf litter invertebrates were extracted using the Tullgren funnel. Soil physical and chemical parameters were analysed.

The catchment forest near Gohagoda had high nitrate $(0.71 \%)$, phosphate $(0.38 \%)$ and sulphate $(0.07 \%)$ concentrations compared to that of in Udawattekele $(0.036 \%, 0.07 \%$ and $0.03 \%$, respectively) which revealed high pollution rate in Gohagoda. This data coincided with the invertebrate diversity in the two areas, Fifteen different invertebrate phyla were excavated and amongst them Collembola, Acarina and Nematoda were the dominant phyla in both forests. Collembolans were significantly high in Udawattakele. The Udawattakele forest area had the highest taxon and individual numbers of invertebrates. The results revealed that according to the Tullgren funnel Bearmaan funnel and $\mathrm{NaCl}$ floatation method Udawattekele forest showed high species diversity by Brillouin, Menhinick, Margalef, Berger-Parker, Shannon and Simpson indices and is significantly high in Udawattakele $(<0.001)$. Overall Udawattekele has a high diversity and evenness than that of Gohagoda area.

This comprehensive analysis of invertebrate diversity shows that it may be used as possible indicator of soil quality. Thus it can be assumed that collembolans can be easily assessed and used as probable indicators of pollution. Therefore incorporating the chemical and biological data gives very promising and reliable conclusions about the degree of soil pollution. Soil invertebrates should also be considered as a resource that needs to be properly managed to enhance ecosystem services.

Keywords: Soil invertebrates, Diversity, Gohagoda, Udawattakele

Proceedings of the International Forestry and Environment Symposium 2016, Department of Forestry and Environmental Science, University of Sri Jayewardenepura, Sri Lanka. 